\title{
Endoscopic Ultrasound-guided Gastroenterostomy: A Promising Alternative to Surgery
}

\author{
Guoxin Wang, Xiang Liu, Sheng Wang, Nan Ge, Jintao Guo, Siyu Sun \\ Endoscopy Center, Shengjing Hospital of China Medical University, \\ Shenyang 110004, Liaoning Province, China
}

\begin{abstract}
Recently, with the advancement of techniques, endoscopic ultrasound-guided therapies have shown distinct advantages, especially in relieving benign and malignant gastric outlet obstruction (GOO), as well as in postoperative pancreaticobiliary diseases. Herein, we present five currently used approaches in endoscopic ultrasound-guided gastroenterostomy (EUS-GE) using lumenapposing biflanged metal stents (LAMS), along with several examples of LAMS-based EUS treatment of pancreaticobiliary diseases. Compared with traditional treatment methods, EUSguided procedures have - to some degree - shown higher success rates, both technical and clinical. Moreover, EUS-guided therapies reduce the risk of multiple surgical adverse events, including delayed gastric emptying, prolonged hospital stay, increased costs, and delay in cancer treatment. Particularly in terms of postoperative pancreaticobiliary diseases, EUSguided therapy has assumed an essential role as a treatment option in cases where traditional methods are difficult to perform. Nevertheless, EUS-guided gastrointestinal procedures are still relatively new, with some clinical failures, and additional prospective clinical trials are warranted.
\end{abstract}

Key words: endoscopic ultrasound, endoscopic ultrasound-guided gastroenterostomy, gastrojejunostomy, stents

Address for Correspondence: Prof. Siyu Sun, MD, Endoscopy Center, Shengjing Hospital of China Medical University, No. 36, Sanhao Street,

Shenyang 110004, Liaoning Province,

China

E-mail: sunsy@sj-hospital.org

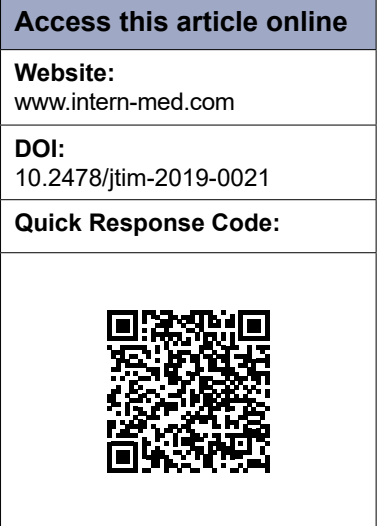

\section{INTRODUCTION}

Surgical gastroenterostomy has been the standard palliative therapy for gastric outlet obstruction (GOO) due to malignant and benign diseases and postoperative pancreaticobiliary complications. Endoscopic intervention is an alternative treatment option for GOO, which is divided into two approaches - the placement of enteric self-expanding metal stents (SEMS) across the stricture and endoscopic ultrasound-guided gastroenterostomy (EUS-GE) using metal stents. Enteric SEMS placement may be complicated due to the recurrent obstruction caused by either stent migration or tumor infiltration. ${ }^{[1,2]}$ Therefore, EUS-GE may be ideal for GOO because of the short anastomotic length of the gastroenterostomy and the minimally invasive nature of the endoscopic intervention. ${ }^{[3-9]}$ This procedure was first introduced in 2002. ${ }^{[10]}$ Common causes of GOO include gastric or duodenal cancer, pancreatitis, periampullary cancer, pancreatic cancer, bile duct cancer, gallbladder cancer, and postoperative therapy, among others. ${ }^{[8,11-13]}$ Symptomatic GOO is amenable to EUS-GE, regardless of the degree of stenosis or the type of disease (benign or malignant). Itoi et al. ${ }^{[2]}$ have recommended that the indications and contraindications for EUS-GE should be based on the stricture site. Obstructions in the antrum of the stomach and those in the first, second, and third portions of the duodenum are indications for EUS-GE, while EUS-GE may not be safe or technically feasible for obstructions in the body of the stomach, the fourth portion of the duodenum, and the proximal jejunum around the ligament of Treitz. ${ }^{[2]}$ According to recent trials, EUS-GE leads to the recovery of oral intake in $90 \%$ of patients, without the risk of tumor ingrowth and/or overgrowth, and meanwhile avoiding the potential morbidity of surgery. . $^{12,12,14-26]}$ 
In this review, we aimed to summarize the current techniques in EUS-GE and to discuss future directions for EUS-GE.

\section{TECHNIQUES IN ENDOSCOPIC ULTRASOUND-GUIDED GASTROENTEROSTOMY: AN OVERVIEW}

The AXIOS ${ }^{\mathrm{TM}}$ lumen-apposing metal stent (LAMS) (15 $\mathrm{mm}$ in diameter and $10 \mathrm{~mm}$ in length; Boston Scientific, Natick, MA, USA) attaches to the gastric and enteric wall and has been shown to be an ideal device for EUS-GE in animal models. ${ }^{[27-34]}$

The AXIOS-EC ${ }^{\mathrm{TM}}$ stent includes an electrocauteryenhanced delivery system that permits stent placement without needle puncture and guidewire placement, and may reduce the risk of missing the target during EUSGE, which can lead to failed EUS-GE with adverse events. ${ }^{[35-42]}$ Bowen et al. ${ }^{[16]}$ successfully used a novel, double-flanged, fully covered, self-expandable metal stent with cautery to refine the EUS-GE procedure in a patient with paraduodenal pancreatitis and walled-off pancreatic necrosis due to biliary pancreatitis. The patient resumed a liquid diet on a postoperative day 2 without any adverse events. ${ }^{[16]}$

Nonetheless, even if an ideal stent is available, EUSGE is still a technically demanding procedure because access to the duodenum and jejunum is difficult and unpredictable. ${ }^{[43]}$ Moreover, given that air insufflation, which can seriously affect the accuracy of ultrasound images, precludes ultrasound imaging, safe puncture into the small bowel is not guaranteed. To overcome this problem, water-filling luminal techniques have been used. Wang et al. ${ }^{[44]}$ reported successful saline with methylene blue-assisted EUS-GE in a 65-year old man with malignant duodenal stenosis after a Roux-en-Y bypass and demonstrated that this method was simple and fast. However, rapid infusion of a large volume of water to sufficiently dilate the small bowel may cause serious adverse events, including hyponatremia, and fluid absorption may result in cardiovascular volume overload. Furthermore, the injection of a large amount of fluid distends not only the targeted portion of small intestine, but also the colon, leading to a risk of puncture into the colon and inadvertent creation of a gastrocolostomy. Several investigators have now developed unique and novel LAMS-based techniques for EUS-GE founded on the approaches above. ${ }^{[2,43,45,46]}$

\section{TRADITIONAL ENDOSCOPIC ULTRASOUND-GUIDED GASTROENTEROSTOMY}

Briefly, the traditional approach to EUS-GE entails direct puncture of a small-bowel loop adjacent to the stomach. ${ }^{[3,4,13,47,48]} \mathrm{A}$ linear echoendoscope is inserted into the stomach, and a duodenal or jejunal loop adjacent to the stomach is identified. After the transgastric puncture of the small bowel with a 19-gauge needle, a contrast is injected to ensure the entry. An enterogram is obtained, and the GE tract is dilated over a wire, followed by placement of a fully covered anastomotic stent. The diameter of the GE tract is gauged to allow the introduction of the anastomotic stent sheath (typically $10.8 \mathrm{~F}$ ), and overly aggressive dilation is avoided to minimize luminal leakage. The flanged LAMS is deployed across the GE tract under combined EUS, fluoroscopic, and endoscopic guidance. The distal anchor flange is deployed first under EUS and fluoroscopic guidance. The proximal anchor flange is then deployed under endoscopic guidance. Usually, the procedure requires a transgastric puncture. ${ }^{[49]}$ Rodrigues-Pinto et al. ${ }^{[4]}$ have reported that retrograde EUS-GE performed from the duodenum to the stomach is also feasible, with a lesser risk of puncturing the duodenal lumen, which has a small caliber and is mobile.

\section{ASSISTED ENDOSCOPIC ULTRASOUND-GUIDED GASTROENTEROSTOMY}

Given that the traditional EUS-GE is not easily performed because of the blind transgastric puncture, an assisted EUS-GE using a retrieval/dilating balloon catheter, single balloon overtube, nasobiliary drain, and ultraslim endoscope is a good choice. A hydrophilic guidewire is advanced distally into the small bowel under fluoroscopic guidance, allowing the insertion of a retrieval or dilating balloon catheter (usually 15 to $18 \mathrm{~mm}$ ); the balloon is passed over the wire and inflated with a contrast medium to serve as the target for transgastric puncture. ${ }^{[50]}$ A linear echoendoscope is then advanced into the stomach, the contrast-inflated balloon is identified under echosonographic and fluoroscopic visualization, and a 19-G needle is used to puncture the balloon. The balloon burst indicates the correct positioning of the needle tip within the small bowel lumen. The remaining steps are similar to the traditional EUS-GE technique.

Advancement of the dilating balloon over the guidewire can be challenging because of the looping of the wire 
in the stomach and flaccidity of the balloon shaft, and additional assistive tools may be required. Another challenge is the potential loss of visualization and access to the small bowel due to the advancement of the wire through the needle pushing the small bowel away from the stomach. Both the need for extra steps and the loss of visualization can potentially result in technical failure and stent misdeployment. ${ }^{[36,39,40]}$

\section{RENDEZVOUS ENDOSCOPIC ULTRASOUND-GUIDED GASTROENTEROSTOMY}

This technique consists of capturing the guidewire in the duodenum or proximal jejunum and pulling it back through the obstruction and out of the mouth, rather than passing the guidewire downstream into the jejunum, thus securing it at both ends. ${ }^{[51]}$ The specific steps include coiling the guidewire within the dilating balloon itself and trapping the wire with a snare or stone retrieval basket, or with an ultra-slim gastroscope and pediatric forceps. The LAMS can be deployed over this fixed guidewire from either end to create the gastroenterostomy. However, the multiple steps again create various challenges.

\section{ENDOSCOPIC ULTRASOUND- GUIDED BALLOON-OCCLUDED GASTROJEJUNOSTOMY BYPASS}

EUS-guided balloon-occluded gastrojejunostomy bypass (EPASS) was devised on the basis of animal studies. ${ }^{[2,52-55]}$ It is performed using a cautery tip-equipped fully covered LAMS and a special double-balloon enteric tube that traps water between the 2 balloons, thus dilating only the intestinal segment needed for the transgastric puncture. ${ }^{[53]}$ The procedure is similar to assisted EUS-GE using other instruments. EPASS is performed by either a onestep procedure (freestyle technique), using the direct electrocautery-enhanced tip delivery system, or a twostep procedure (standard technique), which is a more conventional method. ${ }^{[56-59]}$

During a freestyle EPASS, the AXIOS-EC ${ }^{\mathrm{TM}}$ stent is directly advanced into the distended duodenum or jejunum while applying current. The stent is deployed across the GE tract under combined EUS, fluoroscopic, and endoscopic guidance. Finally, the deployed stent lumen is dilated to 10 $\mathrm{mm}$ with a dilating balloon.

A follow-up upper GI examination is required after EUSGE, usually using water-soluble contrast to evaluate the stent function by confirming that the contrast medium is flowing in the jejunum. ${ }^{[50]}$ Other examinations, such as $\mathrm{CT}$, are also important. We usually evaluate the technical success of EUS-GE in terms of adequate positioning and deployment of the stent as determined endoscopically and radiologically, and clinical success is defined by the patient's ability to tolerate oral intake without vomiting. ${ }^{[60]}$

\section{ONE-STEP ENDOSCOPIC ULTRASOUND-GUIDED GASTROENTEROSTOMY: OTHER APPLICATIONS}

Procedures similar to EUS-GE are also applied to other gastrointestinal diseases. Ikeuchi et al. ${ }^{[5]}$ reported a one-step, LAMS-based, EUS-guided gastrojejunostomy for treatment of afferent loop syndrome. The cauteryequipped AXIOS ${ }^{\mathrm{TM}}$ stent was transgastrically and directly advanced into the enlarged afferent loop under EUS guidance using the AutoCut electrosurgical mode without needle puncture, which proved to be safe and efficient. The device eliminated the need for guidewires, balloon catheters, and the advancement of devices over guidewires, and was performed with a single endoscope, making it the most efficient technique described so far. However, one of the challenges with this technique could be an inability to puncture the small bowel.

\section{OUTCOMES OF ENDOSCOPIC ULTRASOUND-GUIDED GASTROENTEROSTOMY}

Since EUS-GE was first reported using the pig model, several clinical trials have demonstrated the feasibility of the technique in humans, with a high success rate. Relatively large studies with novel devices or techniques have shown technical success rates of approximately $90 \%$, regardless of the approach (Table 1). Complications were seen in several cases, but none were serious.

At present, the most common interventions for the treatment of GOO are endoscopic SEMS placement or surgical gastrojejunostomy (SGJ)..$^{[8,61-63]}$ EUS-GE is the latest breakthrough technique for the management of patients with GOO. ${ }^{[18,20,58,64,65]}$ Randomized trials have compared the outcomes of the 3 interventions with mixed results. The main shortcoming of the enteral SEMS placement is recurrent GOO due to tumor ingrowth/ overgrowth. ${ }^{[6]]}$ Chen et al. ${ }^{[67]}$ performed a comparative study between EUS-GE and endoscopic SEMS placement 
and concluded that EUS-GE may be ideal for malignant GOO, with comparable efficacy and safety to endoscopic SEMS placement and fewer recurrences requiring reintervention.

The main limitation of SGJ is its invasive nature, especially in patients with advanced malignancies and poor nutritional status. In addition, SGJ is associated with frequent complications, including perioperative infection and gastroparesis..$^{[8,61-63,68]}$ Khashab et al. ${ }^{[69]}$ conducted an international multicenter comparative trial of EUS-GE versus SGJ for the treatment of malignant GOO and recommended EUS-GE as a non-inferior but less invasive alternative to surgery.

\section{FUTURE DIRECTIONS FOR ENDOSCOPIC ULTRASOUND- GUIDED GASTROENTEROSTOMY}

Kedia et al.$^{[73]}$ have performed EUS-guided biliary access and SEMS placement through the gastric pouch to treat obstructive jaundice after Roux-en-Y gastric bypass. Iwashita et al. ${ }^{[7]}$ have reported using an EUS-guided antegrade approach and temporary metal stent placement to treat biliary stones in the hepatic duct after a Whipple procedure. The use of a fully covered metal stent at the fistula enabled complete stone clearance through the stent with a basket catheter. Moreover, in place of endoscopic retrograde cholangiopancreatography (ERCP), which is challenging in patients with Roux-en-Y gastric bypass, EUS-directed transgastric ERCP (EDGE), using a linear echoendoscope has been used to access the excluded stomach with deployment of a LAMS over a wire to create a gastrogastric or jejunogastric fistula, which allowed passage of the duodenoscope through the LAMS and performance of conventional ERCP. ${ }^{[75]}$ Jah et al..$^{[76]}$ have reported EUSguided drainage of an abdominal fluid collection following a Whipple procedure using an Olympus GF-UCT240 EUS endoscope (GF-UCT240, Olympus, UK), which was passed through the gastrojejunostomy. The serosanguinous collection was completely aspirated using a 19-gauge Echotip-Ultra needle (Wilson-Cook, Ireland) under EUS guidance. The amylase level in the fluid was normal, and all of the cultures were sterile. ${ }^{[7]}$ Especially for pancreatobiliary diseases, Ramesh et al. ${ }^{[77}$ have recommended that traditional per-os EUS should be attempted first for the examination of the body and tail of the pancreas, while laparoscopyassisted pancreatobiliary EUS should be considered as the preferred technique for the examination of the head of the pancreas and the common bile duct.

Perhaps the greatest potential drawback of EUS-GE is the risk of accidental puncture of the transverse colon, which can lie close to the stomach, or the small bowel, which is sensible and tents away easil. Zhang et al. ${ }^{[22,51,78,79]}$ have devised a retrievable puncture anchor (Vedkang Inc., Changzhou, China) for gallbladder puncture in EUS-guided gallbladder drainage. The retrievable anchor is attached to the gallbladder to provide traction, while the gallbladder is punctured and drained using a LAMS. The anchor can be easily removed after the procedure by changing the direction. We are inspired by the ways this new invention might be applied to EUS-GE to provide traction away from the LAMS, pulling the gastric wall closer to the intestinal

\begin{tabular}{|c|c|c|c|c|c|c|c|c|}
\hline Author & Year & Study design & Technique & $\begin{array}{l}\text { Number of } \\
\text { cases }\end{array}$ & $\begin{array}{l}\text { Technical } \\
\text { Success } \\
\text { rate }(\%)\end{array}$ & $\begin{array}{l}\text { Clinical } \\
\text { success } \\
\text { rate }(\%)\end{array}$ & Follow-up & Complications \\
\hline Khashab et al. ${ }^{[6]}$ & 2015 & $\begin{array}{l}\text { Retrospective } \\
\text { clinical study }\end{array}$ & $\begin{array}{l}\text { Direct or balloon- } \\
\text { assisted EUS-GE }\end{array}$ & 10 & $90 \%$ & $90 \%$ & 21 weeks & - \\
\hline Itoi et al. ${ }^{[70]}$ & 2016 & $\begin{array}{l}\text { Prospective } \\
\text { clinical study }\end{array}$ & EPASS & 20 & $90 \%$ & $90 \%$ & 14 weeks & $\begin{array}{l}1 \text { case: } \\
\text { pneumoperitoneum }\end{array}$ \\
\hline Tyberg et al. ${ }^{[71]}$ & 2016 & $\begin{array}{l}\text { Retrospective } \\
\text { clinical study }\end{array}$ & $\begin{array}{l}\text { Water-filled } \\
\text { intestine (various) }\end{array}$ & 26 & $92 \%$ & $85 \%$ & 8 weeks & $\begin{array}{l}1 \text { case: peritonitis } \\
1 \text { case: bleeding } \\
1 \text { case: pain }\end{array}$ \\
\hline $\begin{array}{l}\text { Perez-Miranda } \\
\text { et al. }{ }^{172]}\end{array}$ & 2017 & $\begin{array}{l}\text { Retrospective } \\
\text { comparative } \\
\text { study }\end{array}$ & $\begin{array}{l}\text { Balloon-assisted } \\
\text { EUS-GE }\end{array}$ & $\begin{array}{l}\text { EUS-GE: } 25 \\
\text { Lap-GJ: } 29\end{array}$ & $\begin{array}{l}88 \% \\
100 \%\end{array}$ & $\begin{array}{l}84 \% \\
90 \%\end{array}$ & $\begin{array}{l}8 \text { weeks } \\
38.4 \text { weeks }\end{array}$ & $\begin{array}{l}12 \% \text { (3 cases) } \\
41 \% \text { (12 cases })\end{array}$ \\
\hline Khashab et al. ${ }^{[69]}$ & 2017 & $\begin{array}{l}\text { Retrospective } \\
\text { comparative } \\
\text { study }\end{array}$ & $\begin{array}{l}\text { Direct puncture } \\
\text { or EPASS }\end{array}$ & $\begin{array}{l}\text { EUS-GE: } 30 \\
\text { Surgery: } 63\end{array}$ & $\begin{array}{l}87 \% \\
100 \%\end{array}$ & $\begin{array}{l}87 \% \\
90 \%\end{array}$ & $\begin{array}{l}155 \text { days } \\
196 \text { days }\end{array}$ & $\begin{array}{l}16 \% \\
25 \%\end{array}$ \\
\hline Chen $\mathrm{YI}$ et al. ${ }^{[67]}$ & 2017 & $\begin{array}{l}\text { Retrospective } \\
\text { comparative } \\
\text { study }\end{array}$ & $\begin{array}{l}\text { Direct puncture, } \\
\text { balloon-assisted } \\
\text { EUS-GE and EPASS }\end{array}$ & $\begin{array}{l}\text { EUS-GE: } 30 \\
\text { Enteral stent: } \\
52\end{array}$ & $\begin{array}{l}86.7 \% \\
94.2 \%\end{array}$ & $\begin{array}{l}83.3 \% \\
67.3 \%\end{array}$ & $\begin{array}{l}103 \text { days } \\
23.5 \text { days }\end{array}$ & $\begin{array}{l}\text { Re-intervention } \\
4 \% \\
28.6 \%\end{array}$ \\
\hline
\end{tabular}

EUS-GE: endoscopic-ultrasound-guided gastroenterostomy; EPASS: endoscopic ultrasound-guided balloon-occluded gastrojejunostomy bypass; Lap-GJ: laparoscopic gastrojejunostomy. 
wall, ${ }^{\left[{ }^{[0]}\right]}$ and potentially increasing the probability of success while making the procedure safer and simpler. ${ }^{[81]}$

We anticipate that in the near future, many patients suffering from malignant GOO will benefit from a safe GE that permits both secure anastomosis and passage of food. In addition, we believe that an endoscopic gastric bypass procedure using a simple anastomosis method with a LAMS has the potential to be a minimally invasive treatment strategy for obesity and type 2 diabetes. The global prevalence of these metabolic diseases has increased exponentially, and conventional bariatric surgery is currently the only treatment that reliably results in large, sustained weight loss and control of intractable type-2 diabetes. ${ }^{[82,83]}$ However, bariatric surgery carries considerable perioperative risk, and there is a great need for minimally invasive weight-loss procedures in the treatment sequence. ${ }^{[5]}$

\section{CONCLUSION}

EUS-GE is a promising new technique for the treatment of benign and malignant GOO, although it is palliative only and is currently used mainly as an alternative for patients without other good treatment options. Limitations such as the risk of puncture of the small bowel, the necessity for stent removal after the procedure, and so on, need more investigation. Nevertheless, since EUS-GE was introduced in 2002, great improvements have been made, new techniques are regularly put forward, and treatment methods based on EUS-GE that are used for other gastrointestinal and biliary diseases especially support the suitability of EUS-GE in the clinical setting. ${ }^{[84]}$ Thus, additional prospective, multicenter trials are justified for the advancement of EUS-GE.

\section{Conflict of Interest}

None declared.

\section{REFERENCE}

1. Irani S, Baron TH, Itoi T, Khashab MA. Endoscopic gastroenterostomy: techniques and review. Curr Opin Gastroenterol 2017;33:320-9.

2. Itoi T, Baron TH, Khashab MA, Tsuchiya T, Irani S, Dhir V, et al. Technical review of endoscopic ultrasonography-guided gastroenterostomy in 2017. Dig Endosc 2017;29:495-502.

3. Chatterjee S, Ibrahim B, Charnley RM, Scott J, Nayar M. Endoscopic ultrasound-guided gastroenterostomy for palliative drainage of an obstructed hepaticojejunostomy loop. Endoscopy 2011;43 UCTN:E1-2.

4. Binmoeller KF, Shah JN. Endoscopic ultrasound-guided gastroenterostomy using novel tools designed for transluminal therapy: a porcine study. Endoscopy 2012;44:499-503.

5. Khashab MA, Baron TH, Binmoeller KF, Itoi T. EUS-guided gastroenterostomy: a new promising technique in evolution. Gastrointest Endosc 2015;81:1234-6.
6. Khashab MA, Kumbhari V, Grimm IS, Ngamruengphong S, Aguila G, El Zein M, et al. EUS-guided gastroenterostomy: the first U.S. clinical experience (with video). Gastrointest Endosc 2015;82:932-8.

7. Taunk P, Cosgrove N, Loren DE, Kowalski T, Siddiqui AA. Endoscopic ultrasound-guided gastroenterostomy using a lumen-apposing selfexpanding metal stent for decompression of afferent loop obstruction. Endoscopy 2015;47 UCTN:E395-6.

8. Kovacevic B, Vilmann P, Karstensen JG. Gastric outlet obstruction syndrome due to an obstructed hepaticojejunostomy loop treated by one-step endoscopic ultrasound-guided gastroenterostomy. Endoscopy 2016;48 Suppl 1:E103-4.

9. Ngamruengphong S, Kumbhari V, Tieu AH, Haito-Chavez Y, Bukhari M, Hajiyeva G, et al. A novel "balloon/snare apparatus" technique to facilitate easy creation of fistula tract during EUS-guided gastroenterostomy. Gastrointest Endosc 2016;84:527.

10. Fritscher-Ravens A, Mosse CA, Mills TN, Mukherjee D, Park PO, Swain P. A through-the-scope device for suturing and tissue approximation under EUS control. Gastrointest Endosc 2002;56:737-42.

11. Brewer Gutierrez OI, Nieto J, Irani S, James T, Pieratti Bueno R, Chen YI, et al. Double endoscopic bypass for gastric outlet obstruction and biliary obstruction. Endosc Int Open 2017;5:E893-9.

12. Tringali A, Giannetti A, Adler DG. Endoscopic management of gastric outlet obstruction disease. Ann Gastroenterol 2019;32:330-7.

13. Bahra M, Jacob D. Surgical palliation of advanced pancreatic cancer. Recent Results Cancer Res 2008;177:111-20.

14. Guo J, Giovannini M, Sahai AV, Saftoiu A, Dietrich CF, Santo E, et al. A multi-institution consensus on how to perform EUS-guided biliary drainage for malignant biliary obstruction. Endosc Ultrasound 2018;7:356-65.

15. Yamauchi H, Kida M, Miyazawa S, Okuwaki K, Iwai T, Imaizumi H, et al. Endoscopic ultrasound-guided antegrade metal stent placement using the stent-in-stent technique in a patient with malignant hilar biliary obstruction. Endosc Ultrasound 2018;7:204-6.

16. Duan B, Guo J, Ge N, Liu X, Wang S, Wang G, et al. Preliminary use of a double-flanged, fully covered, self-expandable, metal stent with cautery in endoscopic ultrasound-guided gastroenterostomy. Endoscopy 2018;50:E29-31.

17. Mahler MA, Prieto RG, Oria I, Villa-Gomez G, Vidales G, Perez-Miranda M. Single-session EUS-guided hepaticogastrostomy and dual-scope gastroenterostomy: a modified technique for palliative double endoscopic biliary and gastric bypass. Endoscopy 2018;50:78-9.

18. Mussetto A, Fugazza A, Fuccio L, Triossi O, Repici A, Anderloni A. Current uses and outcomes of lumen-apposing metal stents. Ann Gastroenterol 2018;31:535-40.

19. Parekh PJ, Shakhatreh MH, Yeaton P. A tale of two LAMS: a report of benign tissue ingrowth resulting in recurrent gastric outlet obstruction. Endosc Int Open 2018;6:E1390-4.

20. Siddiqui UD, Levy MJ. EUS-Guided Transluminal Interventions. Gastroenterology 2018;154:1911-24.

21. Ge PS, Young JY, Dong W, Thompson CC. EUS-guided gastroenterostomy versus enteral stent placement for palliation of malignant gastric outlet obstruction. Surg Endosc 2019.

22. Hu J, Zhang K, Sun S. Endoscopic ultrasound-guided retrievable puncture anchor-assisted gastroenterostomy. Dig Endosc 2019;31:e11-2.

23. Kerdsirichairat T, Irani S, Yang J, Brewer Gutierrez OI, Moran R, Sanaei $\mathrm{O}$, et al. Durability and long-term outcomes of direct EUS-guided gastroenterostomy using lumen-apposing metal stents for gastric outlet obstruction. Endosc Int Open 2019;7:E144-50.

24. Ligresti D, Amata M, Barresi L, Granata A, Traina M, Tarantino I. The lumen-apposing metal stent (LAMS)-in-LAMS technique as an intraprocedural rescue treatment during endoscopic ultrasound-guided gastroenterostomy. Endoscopy 2019.

25. Sakamoto Y, Hijioka S, Maruki Y, Ohba A, Nagashio Y, Okusaka $\mathrm{T}$, et al. Endoscopic ultrasound-guided gastroenterostomy using a 
metal stent for the treatment of afferent loop syndrome. Endoscopy 2019;51:E153-5.

26. Wang W, Qi K, Jin Z, Li Z. Endoscopic exchange of a lumen-apposing metal stent after endoscopic ultrasound-guided gastroenterostomy in severe acute pancreatitis. Endoscopy 2019;51:E18-9.

27. Saumoy M, Arvanitakis M, Kahaleh M. Pancreatic fluid collections and necrosectomy with plastic stents versus lumen-apposing stents. Endosc Ultrasound 2017;6:S132-7.

28. Manvar A, Karia K, Ho S. Endoscopic ultrasound-guided drainage of pelvic abscesses with lumen-apposing metal stents. Endosc Ultrasound 2017;6:217-8.

29. Rinninella E, Kunda R, Dollhopf M, Sanchez-Yague A, Will U, Tarantino $\mathrm{I}$, et al. EUS-guided drainage of pancreatic fluid collections using a novel lumen-apposing metal stent on an electrocautery-enhanced delivery system: a large retrospective study (with video). Gastrointest Endosc 2015;82:1039-46.

30. Gornals JB, Consiglieri CF, Busquets J, Salord S, de-la-Hera M, Secanella $\mathrm{L}$, et al. Endoscopic necrosectomy of walled-off pancreatic necrosis using a lumen-apposing metal stent and irrigation technique. Surg Endosc 2016;30:2592-602.

31. Kunda R, Pérez-Miranda M, Will U, Ullrich S, Brenke D, Dollhopf M, et al. EUS-guided choledochoduodenostomy for malignant distal biliary obstruction using a lumen-apposing fully covered metal stent after failed ERCP. Surg Endosc 2016;30:5002-8.

32. Sharaiha RZ, Tyberg A, Khashab MA, Kumta NA, Karia K, Nieto J, et al. Endoscopic therapy with lumen-apposing metal stents is safe and effective for patients with pancreatic walled-off necrosis. Clin Gastroenterol Hepatol 2016;14:1797-803.

33. Siddiqui AA, Adler DG, Nieto J, Shah JN, Binmoeller KF, Kane S, et al. EUS-guided drainage of peripancreatic fluid collections and necrosis by using a novel lumen-apposing stent: a large retrospective, multicenter US experience (with videos). Gastrointest Endosc 2016;83:699-707.

34. Tsuchiya T, Teoh AYB, Itoi T, Yamao K, Hara K, Nakai Y, Isayama $\mathrm{H}$, et al. Long-term outcomes of EUS-guided choledochoduodenostomy using a lumen-apposing metal stent for malignant distal biliary obstruction: a prospective multicenter study. Gastrointest Endosc 2018;87:1138-46.

35. Bang JY, Varadarajulu S. Stent Tracker app: Novel method to track patients with indwelling lumen-apposing metal stents. Endosc Ultrasound 2018;7:69-70.

36. Chen Y, Zhu H, Jin Z, Li Z, Du Y. An unusual complication of cardia occlusion with lumen-apposing metal stent therapy for pancreatic pseudocyst. Endosc Ultrasound 2018;7:61-3.

37. Kamata K, Takenaka M, Minaga K, Nakai A, Omoto S, Miyata T, et al. Cystic duct antegrade stenting for cholangitis after the long-term deployment of lumen-apposing metal stents for calculous cholecystitis. Endosc Ultrasound 2018;7:349-50.

38. Adler DG, Mallery S, Amateau S, Nieto J, Taylor LJ, Siddiqui A. A pilot study of a 20-mm lumen-apposing metal stent to treat pancreatic fluid collections: First reported multicenter use of a new device. Endosc Ultrasound 2019;8:136-8.

39. Adler DG, Shah J, Nieto J, Binmoeller K, Bhat Y, Taylor LJ, et al. Placement of lumen-apposing metal stents to drain pseudocysts and walled-off pancreatic necrosis can be safely performed on an outpatient basis: A multicenter study. Endosc Ultrasound 2019;8:36-42.

40. Mohan BP, Asokkumar R, Shakhatreh M, Garg R, Ponnada S, Navaneethan $\mathrm{U}$, et al. Adverse events with lumen-apposing metal stents in endoscopic gallbladder drainage: A systematic review and meta-analysis. Endosc Ultrasound 2019.

41. Nunes G, Marques PP, Patita M, Allen M, Gargate L. EUS-guided recanalization of complete colorectal anastomotic stenosis using a lumenapposing metal stent. Endosc Ultrasound 2019;8:211-2.

42. Li L, Cristofaro S, Qu C, Liang S, Li X, Cai Q. EUS-guided drainage of pancreatic fluid collection with a Hot AXIOS stent in a patient with pancreatitis following distal pancreatectomy (with video). Endosc Ultrasound 2018;7:347-8.

43. Benallal DC, Hoibian S, Caillol F, Bories E, Presenti C, Ratone JP, et al. EUS-guided gastroenterostomy for afferent loop syndrome treatment stent. Endosc Ultrasound 2018;7:418-9.

44. Wang G, Liu X, Wang S, Ge N, Guo J, Sun S. Saline with methylene blue-assisted endoscopic ultrasound-guided gastrojejunostomy using a double-flared fully covered metal stent. Endoscopy 2018;50:E17-9.

45. Nakai $\mathrm{Y}$, Isayama $\mathrm{H}$, Kawakami $\mathrm{H}$, Ishiwatari $\mathrm{H}$, Kitano M, Ito $\mathrm{Y}$, et al. Prospective multicenter study of primary EUS-guided choledochoduodenostomy using a covered metal stent. Endosc Ultrasound 2019;8:111-7.

46. Ogura T, Okuda A, Miyano A, Nishioka N, Higuchi K. Stent release within scope channel technique to prevent stent migration during EUS-guided hepaticogastrostomy (with video). Endosc Ultrasound 2018;7:67-8.

47. Khashab MA, Tieu AH, Azola A, Ngamruengphong S, El Zein MH, Kumbhari V. EUS-guided gastrojejunostomy for management of complete gastric outlet obstruction. Gastrointest Endosc 2015;82:745.

48. Sahai AV. EUS is trending! Endosc Ultrasound 2018;7:353-5.

49. Rodrigues-Pinto E, Grimm IS, Baron TH. Endoscopic ultrasound (EUS)guided duodenogastroenterostomy: why not do it from the other side? Endoscopy 2015;47 UCTN:E594-5.

50. Law R, Grimm IS, Baron TH. EUS-guided gastroduodenostomy for gastric outlet obstruction related to chronic pancreatitis. Gastrointest Endosc 2015;82:567-8.

51. Kawakubo K, Kuwatani M, Kato S, Sugiura R, Sano I, Sakamoto N. Direct puncture of the ampulla as a modified Endoscopic ultrasound-guided rendezvous technique. Endosc Ultrasound 2018;7:133-4.

52. Itoi T, Ishii K, Tanaka R, Umeda J, Tonozuka R. Current status and perspective of endoscopic ultrasonography-guided gastrojejunostomy: endoscopic ultrasonography-guided double-balloon-occluded gastrojejunostomy (with videos). J Hepatobiliary Pancreat Sci 2015;22:3-11.

53. Itoi T, Tsuchiya T, Tonozuka R, Ijima M, Kusano C. Novel EUS-guided double-balloon-occluded gastrojejunostomy bypass. Gastrointest Endosc 2016;83:461-2.

54. Nakai Y, Hamada T, Isayama H, Itoi T, Koike K. Endoscopic management of combined malignant biliary and gastric outlet obstruction. Dig Endosc 2017;29:16-25.

55. Rimbas M, Larghi A, Costamagna G. Endoscopic ultrasound-guided gastroenterostomy: Are we ready for prime time? Endosc Ultrasound 2017;6:235-40.

56. Ikeuchi N, Itoi T, Tsuchiya T, Nagakawa Y, Tsuchida A. One-step EUSguided gastrojejunostomy with use of lumen-apposing metal stent for afferent loop syndrome treatment. Gastrointest Endosc 2015;82:166.

57. Tarantino I, Ligresti D, Barresi L, Curcio G, Granata A, Traina M. Onestep, exchange-free, single-balloon-assisted endoscopic ultrasoundguided gastroenterostomy with lumen-apposing metal stent in malignant gastric outlet obstruction. Endoscopy 2017;49:E92-4.

58. Coro O, Caillol F, Poincloux L, Bories E, Pesenti C, Ratone JP, et al. Hepaticogastrostomy under EUS guidance for a patient with a history of bypass surgery with a new stent design (with video). Endosc Ultrasound 2019;8:66-8.

59. Moran RA, Ngamruengphong S, Sanaei O, Fayad L, Singh VK, Kumbhari $\mathrm{V}$, et al. EUS-directed transgastric access to the excluded stomach to facilitate pancreaticobiliary interventions in patients with Roux-en-Y gastric bypass anatomy. Endosc Ultrasound 2019;8:139-45.

60. Chen YI, Kunda R, Storm AC, Aridi HD, Thompson CC, Nieto J, et al. EUS-guided gastroenterostomy: a multicenter study comparing the direct and balloon-assisted techniques. Gastrointest Endosc 2018;87:1215-21.

61. Zhu L, Mo Z, Yang X, Liu S, Wang G, Li P, et al. Effect of laparoscopic Roux-en- $Y$ gastroenterostomy with $\mathrm{BMI}<35 \mathrm{~kg} / \mathrm{m}(2)$ in type 2 diabetes mellitus. Obes Surg 2012;22:1562-7.

62. Karaman K, Yalkin O, Ercan M, Demir H, Altintoprak F, Zengin I. Retroanastomotic hernia after Moynihan's gastroenterostomy. World J Gastrointest Surg 2014;6:187-9. 
63. Barreira MA, Siveira DG, Rocha HAL, Moura Junior LG, Mesquita CJG, Borges GCO. Evaluation tool for a gastroenterostomy simulated training1. Acta Cir Bras 2019;34:e201900308.

64. Yamamoto K, Itoi T, Tsuchiya $\mathrm{T}$, Tanaka R, Tonozuka R, Honjo M, et al. EUS-guided antegrade metal stenting with hepaticoenterostomy using a dedicated plastic stent with a review of the literature (with video). Endosc Ultrasound 2018;7:404-12.

65. Okuwaki K, Yamauchi H, Kida M, Imaizumi H, Matsumoto T, Tadehara $\mathrm{M}$, et al. The large-balloon occlusion technique: A new method for conversion to EUS-guided hepaticogastrostomy in patient with prior self-expanding metal stent placement. Endosc Ultrasound 2019;8:209-10.

66. Jeurnink SM, Steyerberg EW, van Hooft JE, van Eijck CH, Schwartz MP, Vleggaar FP, et al. Surgical gastrojejunostomy or endoscopic stent placement for the palliation of malignant gastric outlet obstruction (SUSTENT study): a multicenter randomized trial. Gastrointest Endosc 2010;71:490-9.

67. Chen YI, Itoi T, Baron TH, Nieto J, Haito-Chavez Y, Grimm IS, et al. EUS-guided gastroenterostomy is comparable to enteral stenting with fewer re-interventions in malignant gastric outlet obstruction. Surg Endosc 2017;31:2946-52.

68. Khashab M, Alawad AS, Shin EJ, Kim K, Bourdel N, Singh VK, et al. Enteral stenting versus gastrojejunostomy for palliation of malignant gastric outlet obstruction. Surg Endosc 2013;27:2068-75.

69. Khashab MA, Bukhari M, Baron TH, Nieto J, El Zein M, Chen YI, et al. International multicenter comparative trial of endoscopic ultrasonography-guided gastroenterostomy versus surgical gastrojejunostomy for the treatment of malignant gastric outlet obstruction. Endosc Int Open 2017;5:E275-81.

70. Itoi T, Ishii K, Ikeuchi N, Sofuni A, Gotoda T, Moriyasu F, et al. Prospective evaluation of endoscopic ultrasonography-guided double-balloonoccluded gastrojejunostomy bypass (EPASS) for malignant gastric outlet obstruction. Gut 2016;65:193-5.

71. Tyberg A, Perez-Miranda M, Sanchez-Ocana R, Penas I, de la Serna C, Shah J, et al. Endoscopic ultrasound-guided gastrojejunostomy with a lumen-apposing metal stent: a multicenter, international experience. Endosc Int Open 2016;4:E276-81.

72. Perez-Miranda M, Tyberg A, Poletto D, Toscano E, Gaidhane M, Desai AP, et al. EUS-guided Gastrojejunostomy Versus Laparoscopic Gastrojejunostomy: An International Collaborative Study. J Clin Gastroenterol 2017;51:896-9.
73. Kedia P, Tyberg A, Kumta NA, Gaidhane M, Karia K, Sharaiha RZ, et al. EUS-directed transgastric ERCP for Roux-en-Y gastric bypass anatomy: a minimally invasive approach. Gastrointest Endosc 2015;82:560-5.

74. Iwashita T, Yasuda I, Mukai T, Doi S, Uemura S, Mabuchi M, et al. Successful management of biliary stones in the hepatic duct after a Whipple procedure by using an EUS-guided antegrade approach and temporary metal stent placement. Gastrointest Endosc 2014;80:337.

75. Franco MC, Safatle-Ribeiro AV, Gusmon CC, Ribeiro MS, Maluf-Filho F. ERCP with balloon-overtube-assisted enteroscopy in postsurgical anatomy. Gastrointest Endosc 2016;83:462-3.

76. Jah A, Jamieson N, Huguet E, Griffiths W, Carroll N, Praseedom R. Endoscopic ultrasound-guided drainage of an abdominal fluid collection following Whipple's resection. World J Gastroenterol 2008;14:6867-8.

77. Ramesh J, Christein J, Varadarajulu S. The concept of laparoscopy-assisted pancreatobiliary EUS (LAP-EUS). J Gastrointest Surg 2013;17:1020-3.

78. Zhang K, Guo J, Sun S. Retrievable puncture anchor-assisted gallbladder drainage: Throwing the gallbladder a lifeline. Endosc Ultrasound 2017;6:355-8.

79. Cheng B, Li D, Wu X, Zhang Z, Zhang M, Yang M, et al. Stent drainage achieved by endoscopic ultrasonography-guided puncture from duodenal bulb to the minor pancreatic duct for the treatment of acute epigastric pain in a patient with pancreas divisum. Endosc Ultrasound 2018;7:130-2.

80. De Cobelli F, Marra P, Diana P, Brembilla G, Venturini M. Therapeutic EUS: Biliary drainage - The interventional radiologist's perspective. Endosc Ultrasound 2017;6:S127-31.

81. Rimbas M, Larghi A, Kunda R. EUS-guided biliary drainage: Is it ready for prime time? Endosc Ultrasound 2017;6:S122-6.

82. Yurcisin BM, Gaddor MM, DeMaria EJ. Obesity and bariatric surgery. Clinics in chest medicine 2009;30:539-53.

83. Wadden TA, Brownell KD, Foster GD. Obesity: responding to the global epidemic. J Consult Clin Psychol 2002;70:510.

84. Adler DG, Siddiqui AA. Nobody really knows how to perform endoscopic necrosectomy. Endosc Ultrasound 2017;6:147-8.

How to cite this article: Wang G, Liu X, Wang S, Ge N, Guo N, Sun S. Endoscopic Ultrasound-guided Gastroenterostomy: A Promising Alternative to Surgery. J Transl Int Med 2019; 7: 93-9. 